British Journal of Nutrition (2022), 127, 481-489

doi:10.1017/S0007114521001215

(C) The Author(s), 2021. Published by Cambridge University Press on behalf of The Nutrition Society. This is an Open Access article, distributed under the terms of the Creative Commons Attribution licence (http://creativecommons.org/licenses/by/4.0/), which permits unrestricted re-use, distribution, and reproduction in any medium, provided the original work is properly cited.

\title{
Fructose malabsorption: causes, diagnosis and treatment
}

\author{
Miles Benardout ${ }^{1 *}$, Adam Le Gresley ${ }^{1}$, Amr ElShaer $^{2}$ and Stephen P. Wren ${ }^{1 *}$ \\ ${ }^{1}$ Department of Chemical and Pharmaceutical Sciences, Faculty of Science, Engineering and Computing, Kingston University \\ London, Penryhn Road, Surrey KT12EE, UK \\ ${ }^{2}$ Department of Pharmacy, Faculty of Science, Engineering and Computing, Kingston University London, Penrybn Road, Surrey \\ KT12EE, UK
}

(Submitted 14 October 2020 - Final revision received 19 February 2021 - Accepted 28 March 2021 - First published online 5 April 2021)

\section{Abstract}

This review intends to act as an overview of fructose malabsorption (FM) and its role in the aetiology of diseases including, but not limited to, irritable bowel syndrome (IBS) and infantile colic and the relationship between fructose absorption and the propagation of some cancers. IBS results in a variety of symptoms including stomach pains, cramps and bloating. Patients can be categorised into two groups, depending on whether the patients' experiences either constipation (IBS-C) or diarrhoea (IBS-D). FM has been proposed as a potential cause of IBS-D and other diseases, such as infantile colic. However, our knowledge of FM is limited by our understanding of the biochemistry related to the absorption of fructose in the small intestine and FM's relationship with small intestinal bacterial overgrowth. It is important to consider the dietary effects on FM and most importantly, the quantity of excess free fructose consumed. The diagnosis of FM is difficult and often requires indirect means that may result in false positives. Current treatments of FM include dietary intervention, such as low fermentable oligo-, di-, monosaccharides and polyols diets and enzymatic treatments, such as the use of xylose isomerase. More research is needed to accurately diagnose and effectively treat FM. This review is designed with the goal of providing a detailed outline of the issues regarding the causes, diagnosis and treatment of FM.

Key words: Fructose malabsorption: Irritable bowel syndrome: Small intestines: Diagnosis: Breath hydrogen testing

It is estimated that irritable bowel syndrome (IBS) affects around $11 \%$ of the global population ${ }^{(1)}$. IBS has symptoms including stomach pains and cramps, bloating, diarrhoea and constipation. Although being a common disease, the exact causes of IBS are typically described as a gut-brain disorder; however, this notion has been challenged in recent years and a number of new potential causes, including anxiety and depression, gut bile malabsorption and inflammation and infection of the nervous system, have been proposed ${ }^{(2)}$. Fructose malabsorption (FM) has also been suggested as a potential cause of $\operatorname{IBS}^{(3)}$. FM is believed to affect one in three patients with IBS and is caused by the incomplete absorption of fructose in the small intestine (SI), leading to gastrointestinal (GI) complaints, and has been linked to other diseases, such as early-stage depression ${ }^{(4-6)}$. FM can develop as a result of primary causes, such as congenital deficiency, or by secondary means, including, but not limited to intestinal damage, acute gastroenteritis, medication, coeliac disease, Crohn's diseases and use of prebiotics. However, due to a lack of knowledge regarding the mechanism of fructose absorption to date, it has been difficult to accurately diagnose and treat $\mathrm{FM}^{(7)}$. In the past few decades, there has been an increase in the amount of fructose consumed, particularly due to high fructose corn syrup (HFCS) and increased consumption of HFCS-rich soft drinks, especially by younger people ${ }^{(8)}$. It has been noted in a survey between 1994 and 1996 that the consumption of artificial sweeteners, including HFCS, results in $1330.5 \mathrm{~kJ}$ daily of dietary consumption for US Americans above the age of 2 years; this accounts for $16 \%$ of all caloric intake daily ${ }^{(9)}$.

A variety of diseases can result in the malabsorption of sugars, including lactose intolerance, congenital glucose-galactose malabsorption and congenital sucrase-isomaltase deficiency, resulting in the malabsorption of lactose, galactose and maltose, respectively ${ }^{(10,11)}$. However, this review will focus on FM and the specific factors affecting the treatment of FM.

\section{Fructose chemistry}

Fructose, a ketonic monosaccharide, is able to be directly absorbed into blood from the GI tract; it is one of three dietary

Abbreviations: DP, depolymerisation; EFF, excess free fructose; FM, fructose malabsorption; FODMAP, fermentable oligo-, di-, monosaccharides and polyols; GI, gastrointestinal; HBT, hydrogen breath test; HFCS, high fructose corn syrup; IBS, irritable bowel syndrome; SI, small intestine; SIBO, small intestinal bacterial overgrowth.

* Corresponding authors: Miles Benardout; email k1606973@kingston.ac.uk and Dr. Stephen P. Wren, email s.wren@kingston.ac.uk 
monosaccharides that possess this property, alongside glucose and galactose. Fructose is commonly obtained from sugar beets, sugar cane and maize and is the sweetest of all monosaccharides $^{(12)}$. The solubility and sweetness of fructose have been exploited by the food industry in artificial sweeteners, with particular popularity around the use of HFCS, a mixture of glucose and fructose in the monosaccharide form in recent years. Between 1970 and 2004, the share of HFCS as a percentage of total sweetener use has risen from half a percentage point to $42 \%{ }^{(13)}$.

It has been estimated that between 1994 and 1998, the average US American above the age of 2 years consumes $552.3 \mathrm{~kJ}$ of HFCS per day. Added sweeteners contribute to $16 \%$ of this daily energetic intake ${ }^{(14-16)}$. Fructose can be present as a monosaccharide, most abundantly in the furanose form, or as the disaccharide sucrose, in a one to one molecular ratio with glucose. Figure 1 shows the five isomers of fructose; in aqueous solution, fructose exists in the equilibria shown in Fig. 1. The mixture of the five isomers is comprised of $70 \%$ fructopyranose and $22 \%$ fructofuranose; the remaining $8 \%$ consists of the other three forms, including acyclic D-fructose. Fructose can also exist in two anomeric states, $\alpha$ and $\beta$, and these are also shown in Fig. 1.

\section{Causes of fructose malabsorption}

FM is caused by the failure to effectively absorb fructose through the enterocytes lining the SI. This results in the accumulation of fructose in the intestinal lumen. The resulting change in osmotic pressure causes the flow of water into the lumen, thus leading to the symptoms associated with IBS. The underlying factors related to the cause of FM will be described in detail in the following section.

\section{Mechanism of fructose absorption}

For healthy patients, serum fructose concentration is around $8 \cdot 1 \pm 1.0 \mu \mathrm{mol} / \mathrm{l}$ and for diabetics, serum fructose concentration is around $12 \cdot 0 \pm \mu \mathrm{mol} / \mathrm{l}^{(17)}$. The current understanding of FM is underpinned by the transport enzymes present on the borders of the enterocytes lining the SI. The two enzymes in question are GLUT2 and GLUT5. The general understanding of the mechanism of absorption for fructose is that GLUT2 is a highcapacity, low-affinity glucose/galactose transporter that can co-transport fructose in a one-to-one ratio ${ }^{(18)}$. GLUT2 is unable to transport fructose without the presence of glucose, although the mechanism for this is currently unknown. However, it is proposed that GLUT5 is able to selectively transport fructose across the apical membrane of the SI. The low capacity of GLUT5 means that excess fructose leads to the overloading of GLUT5, preventing the complete absorption of fructose ${ }^{(19)}$. The presence of excess fructose in the GI tract leads to increased osmotic load, which, in turn, triggers the symptoms associated with $\operatorname{IBS}^{(4)}$. Further research is needed to solidify our understanding of fructose absorptions, so that treatment can be better targeted. One

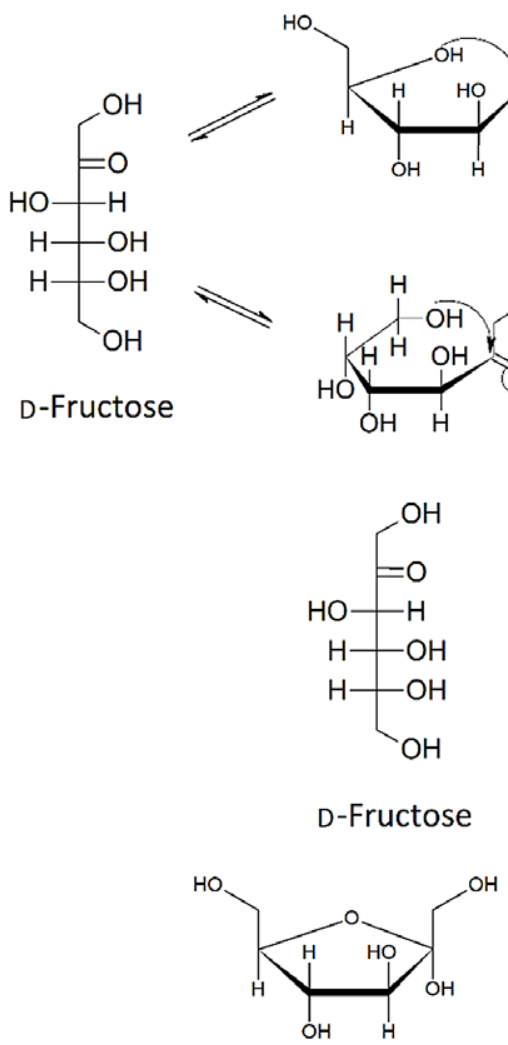

$\alpha$-D-Fructopyranose

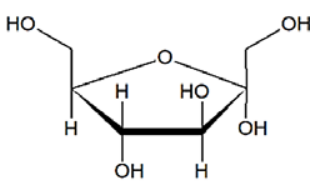

$\alpha$-D-Fructopyranose

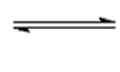<smiles>O=C(CO)C(O)C(O)CO</smiles>

$\alpha$-D-Fructopyranose
L-Fructose

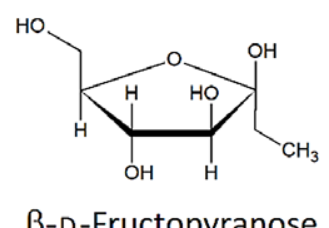

Fig. 1. Structures of the isomers and anomers of fructose. 


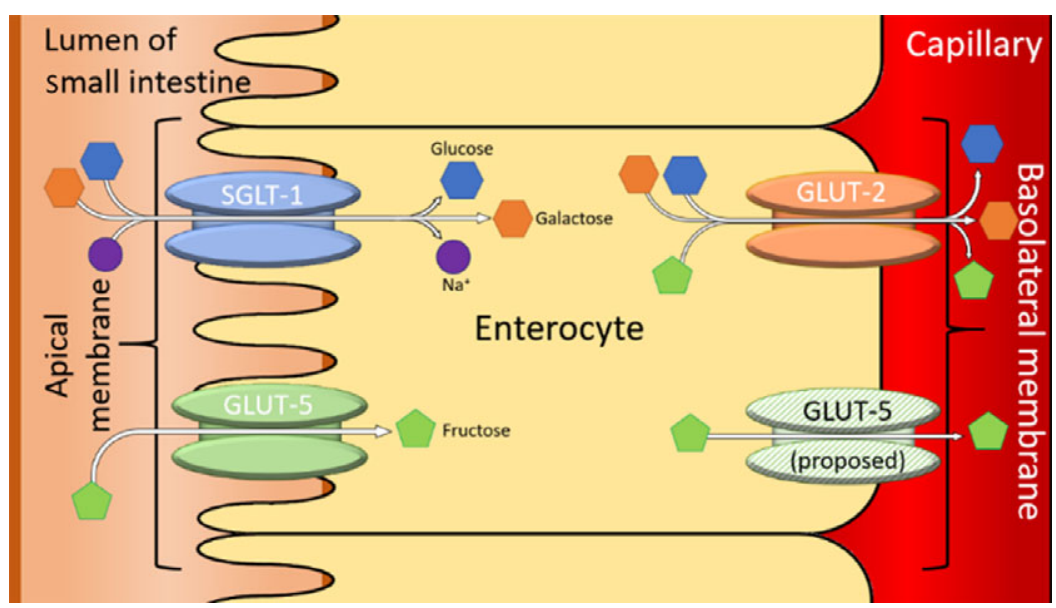

Fig. 2. A simplified diagram of sugar transporters in the enterocytes of the small intestines. Adapted from ${ }^{(21-23)}$. SGLT-1 is a sodium-mediated enzyme related to the facilitated co-transport of glucose and galactose and is not linked to the transportation of fructose ${ }^{(24)}$.

such method could involve targeting the prevention of the fructose accumulation in the GI tract, thus preventing the symptoms resulting from such accumulation. Figure 2 summarises the enzymes involved in the absorption of fructose and other dietary sugars, in the SI. It shows the confirmed and proposed locations of GLUT5 within the enterocyte ${ }^{(20)}$.

A total of six GLUT potentially have the capacity to selectivity transport fructose. These are GLUT 5, 7, 8, 9, 11 and $12^{(20)}$. However, this review will focus primarily on GLUT5, due to its confirmed selectivity for fructose and its high expression within the SI and duodenum.

\section{Expression of GLUT5}

Expression of GLUT5 is coded by the solute carrier family 2, facilitated GLUT member 5 (SLC2A5) gene and although expression is highest in the SI and duodenum, the RNA resulting from SLC2A5 expression is found in other tissue as well ${ }^{(25)}$. Despite glucose being the primary energy source in the brain, RNA production from SLC2A5 has resulted in GLUT5 expression being found in the blood-brain barrier of rats, as well as the microglia and fetal cerebellar Purkinje cells of humans ${ }^{(26-28)}$. GLUT5 is also expressed in the cerebellum of mice and the hippocampus of rats. These cells may be capable of using fructose as a source of energy; however, this is currently unconfirmed. It should be noted the expression of GLUT 5 in the brain is significantly lower than in the $\mathrm{SI}^{(29)}$

Diabetes has a major effect on GLUT5 expression in the SI. It has been found that in type 2 diabetic patients, there is a three- to four-fold increase in the expression of GLUT 5 proteins and mRNA in duodenal and small intestinal cells ${ }^{(29)}$. Reversing blood hyperglycaemia results in the reversal of the elevated levels of GLUT 5 expression ${ }^{(29)}$. A positive link between blood hypertension, linked to diabetes, and up-regulation of GLUT5 has also been investigated ${ }^{(17)}$. However, more research into this finding is required.

The effect diabetes has on serum fructose concentration is currently unclear. Serum fructose concentration and urinary fructose increased significantly in Japanese diabetic patients indicating $\mathrm{FM}^{(30)}$. However, a similar study in Finland, comparing healthy volunteers with type 1 and 2 diabetics, indicated similar concentrations of serum fructose ${ }^{(31,32)}$. These contradictory results complicate what the precise effect of diabetes is on serum fructose concentration. However, it is apparent that fructose may have a key role in the development of metabolic disorders that cause the adverse effects resulting from diabetes.

FM may have a role to play in causing infantile colic ${ }^{(33)}$. It has been noted that in the prenatal and suckling periods of rats, rabbits and humans, GLUT5 levels in the intestine are very low ${ }^{(34)}$. Additionally, a study into breath hydrogen of colic-affected patients indicated an increase in breath hydrogen in children, less than 1 year of age, but not in those 2 years or older ${ }^{(35)}$. These results indicate that GLUT5 is not initially expressed in infants and the resulting FM may result in the colic that many infants suffer from.

Interestingly, elevated levels of GLUT5 mRNA and protein expression have been found in some cancer cell lines. Despite GLUT5's poor expression in typical mammary epithelial cells, high amounts of GLUT5 mRNA and protein expression have been found in the breast carcinoma cell lines MCF-7 and MDA-MB-231, resulting in high fructose transport rates ${ }^{(36)}$, which are models of early and late stage cancer, respectively. GLUT5 knockdown studies have shown inhibition of the growth of both MCF-7 and MDA-MB-231, highlighting the transporter's importance to the cancer cell lines ${ }^{(37)}$.

Large-scale screening of the GLUT family, using western blotting, in both cancerous and normal human tissues showed GLUT5 is significantly overexpressed in $27 \%$ of cancerous tissues tested, including tumours of the brain, breast, colon, liver, lung, testes and uterus, with GLUT5 showing moderate to high amounts of staining in all but one cancer tissues tested ${ }^{(36,37)}$.

Most of the tumours cells presenting an overexpression of GLUT5 additionally possess an elevated rate of fructose uptake and the extensive overexpression of GLUT2 and GLUT5, and indicate that fructose may be preferred as the energy source for the growth and propagation of some tumour cells ${ }^{(38)}$. More research is needed to determine whether this characteristic 
can be exploited for anti-cancer activity. It could be possible that locally inducing FM in cancer cells, may result in apoptosis of such cells. The impact of the GLUT5's presence in some cancerous tissue needs to be fully delineated, to confirm whether GLUT5 can be exploited as a target for novel chemotherapy methods.

\section{Small intestinal bacterial overgrowth}

It has been proposed that some symptoms of IBS may not be as a result of FM, but rather as a result of fructose fermentation by bacteria in the SI and the resulting bacterial respiration ${ }^{(39)}$. These symptoms include bloating and elevated hydrogen breath test (HBT) levels. Hydrogen gas excretion is significantly increased in $84 \%$ of IBS patients after lactulose ingestion (BTLact) and an increase of $75 \%$ after the use of local antibiotics. There is also a strong correlation between the nature of gas excreted and bowel movement patterns ${ }^{(40,41)}$.

The BTLact test is a tool used to assess the prevalence of small intestinal bacterial overgrowth (SIBO) within a patient. When compared with analysing jejune aspiration, BTLact is simpler and more tolerable for patients, providing information quicker to the clinician, since a jejune aspiration testing requires an endoscopic retrieval of jejunal flora and subsequent microbiological culture $^{(41)}$.

BTLact uses the ingestion of lactulose, which cannot be absorbed through the SI, resulting in the lactulose being metabolised by bacterial flora, producing gases, including methane and hydrogen.

The sensitivity of the BTLact test in SIBO diagnosis is reported to be $86 \%$, with $44 \%$ specificity, indicating that some symptoms of IBS may not be due to SIBO exclusively ${ }^{(44-46)}$. This has directed some clinicians to consider that BTLact is not the best method for diagnosing SIBO and they prefer more indirect methods, such as serum vitamin $\mathrm{B}_{12}$ and folate levels instead. It must also be noted that BTLact uses lactulose; this is significant because the flora of the SI is varied and complex (and may respond differently to other sugars, including fructose and fructans). Currently, there is no standardised test for the absorption of fructans and research in the area is limited ${ }^{(47,48)}$.

Fructans are naturally derived carbohydrate storage polymers found in plants. They are fructose polymers with terminal glucose molecules. The degree of depolymerisation (DP), defined as the number of monomers that make up an oligomer or polymer, thereby indicating the length of the oligomer or polymer, can be as low as one and can reach several hundreds ${ }^{(49)}$. A couple of examples of common fructans are sucrose (DP $=$ one) and insulin ( $\mathrm{DP}=$ thirty-five). Fructans are typically found in cereals, onions, asparagus, scorzonera and Jerusalem artichokes, as well as some non-edible plants, for example, chicory ${ }^{(40)}$. Fructans are commonly used as artificial sweeteners ${ }^{(40)}$. It has been shown that dietary fructans can alter the intestinal mucosal environment, releasing mucins and mucosa-associated bifidobacterial in gnotobiotic rats ${ }^{(41)}$. Fermentation patterns of fructans tend to remain fairly consistent regardless of DP; however, there is a significant positive correlation between DP and transit time ${ }^{(51)}$. However, the same study showed that undesired abdominal symptoms only occurred in single doses of fructans greater than $20 \mathrm{~g}$ where given to the participants of a trial ${ }^{(52)}$.

These studies indicate that some symptoms of IBS perhaps are better attributed to SIBO, rather than FM alone. However, it must be noted that the two conditions are not mutually exclusive; rather, it is important to note that a patient with IBS may have SIBO and FM, or only one of the two conditions. Since it is apparent that the symptoms of IBS cannot be exclusively attributed to one of these two causes, the nature of their interactions may cause difficulty when attempting to determine the appropriate therapeutic actions to pursue. This is because certain treatments that are affective for symptoms resulting in SIBO may be ineffective for symptoms resulting from FM and vice versa ${ }^{(53)}$.

It has also been proposed that the uses of prebiotics have a beneficial effect on intestinal health ${ }^{(54)}$. However, this may result in SIBO and the production of unwanted side-effects in patients affected by IBS. Prebiotics can selectively stimulate the growth and activity of gut bifidobacteria and lactobacilli ${ }^{(55,56)}$. Prebiotics are non-digestible, short-chain carbohydrates with a DP between two and approximately sixty. However, this evidence related to non-digestible prebiotics is mostly circumstantial. Oligofructose that has been incubated in vivo with either human saliva or rat pancreatic homogenate has been shown to be 'hardly digested', rather than completely non-digestible ${ }^{(51)}$. This means that oligofructose may contribute to the accumulation of fructose in the GI tract. Prebiotics are relatively simple, water soluble, molecules; therefore, fermentation by GI flora is highly likely.

Human studies have shown a consistent failure to recover inulin and oligofructose in faecal matter, indicating their complete metabolisation by intestinal flora ${ }^{(57)}$. In vitro studies have demonstrated the ability of prebiotics to support intestinal bacteria growth and result in the production of a variety of fermentation-derived end products ${ }^{(58)}$. Two early studies showed the $i n$ vitro utilisation of oligofructose, derived from sucrose, by bifidobacteria. However, oligofructose lacks selectivity towards bifidobacterial species and a variety of enteric bacteria were able to grow on a wide range of prebiotics, in particular species of Bacteroides $^{(14,59)}$. Wang and Gibson later showed that both inulin and oligofructose could selectively promote the growth of bifidobacteria $^{(60)}$. It has been shown that $42 \%$ of patients with FM also have a high prevalence of intestinal parasites, with Giardia intestinalis being present in twenty-six and a half percentage of cases of FM, highlighting a significant association between FM and the presence of intestinal parasites ${ }^{(61)}$.

The main products of the metabolism of prebiotics are SCFA, hydrogen gas, carbon dioxide and bacterial cell mass ${ }^{(62)}$. However, there has been little research into the relationship of the type of carbohydrate and its fermentability. This research could provide profound insight into the effect prebiotics have upon the symptoms of IBS resulting from SIBO.

\section{Trends in the diagnosis of fructose malabsorption}

A number of different factors have been linked to an increased likelihood of developing FM. It is important to consider these factors, as FM is often misdiagnosed, due to the similarity in symptoms with other forms of carbohydrate malabsorption. 
A key difference in FM cases when compared with lactose intolerance and other cases of carbohydrate malabsorption is the relationship between FM and age. A study of 1093 patients showed that the probability of testing positive for FM decreased by a factor of 0.82 per year of age, for patients under the age of 15 years; this trend is not found in cases of lactose intolerance ${ }^{(63)}$. This may be linked with the late expression of fructose-selective GLUT5 enzymes ${ }^{(34)}$.

There may also be a relationship between sex and FM. A study in 2007 showed that women complained more frequently about symptoms associated with FM $(P=0.04)$ as well as presenting a greater number of cases than men $(P=0.0527)^{(64)}$. However, the present study needs expansion to a larger sample size (greater than $n$ 29) and more research is needed to determine whether there is a causal link between sex and FM.

Unfortunately, there has been no research into comparing the pervasiveness of FM between different ethnicities on a national level. Therefore, it is currently difficult to determine any possible correlation between ethnicity and the likelihood of FM.

Diet is a key factor in the prevalence of FM. A study of 3476 patients with FM showed that $52 \%$ of patients consumed a fructose-rich diet, including high consumption of soft drinks, fruit juices, candy and fructose-rich fruits, such as apples, pears, peaches and oranges. The effects of diet on FM will be discussed in more detail later on in this review ${ }^{(65)}$. According to the same study, FM is most commonly accompanied by gastroesophageal reflux disease, followed by lactose intolerance ${ }^{(65)}$. It should be noted again that the symptoms of lactose intolerance are similar to those of FM, which may lead to potential misdiagnosis of FM.

\section{Effect of diet relating to fructose malabsorption}

It is important to consider the trends in fructose consumption and the changes in diet related to sugar that may contribute towards FM and diseases caused, at least in part, by FM.

Logically, it could be expected that high fruit consumption is a primary cause of FM because of its sugar content. However, based upon the hypothesis that the critical factor is the amount of excess free fructose (EFF), many fruits may not fit this criterion. According to a study by Barrett and Gibson on sugar content in fruits, only apples, pears, mangoes and Asian pears have more than a gram of EFF per average serving, potentially leading to FM after consumption. All other fruits contain fructose, with either glucose in excess or a very slight excess in fructose, making them an unlikely factor for $\mathrm{FM}^{(8)}$. Another key component here is the consumption of soft beverages, which often use HFCS as an artificial sweetener, which is high in fructose. Studies by Ventura and Walker have shown that the vast majority of soft drinks in North America contain $\mathrm{EFF}^{(14,62)}$. The study by Ventura assessed that eighteen soft drinks that used HFCS had an average of $1.5 \mathrm{~g}$ of EFF per $100 \mathrm{ml}$; this results in an average of $37 \%$ more fructose than glucose ${ }^{(14)}$. Two notable exceptions are Mexican Coca-Cola and Pepsi throwback, which both use cane sugar, rather than HFCS. Walker's study showed cane sugar has a lower fructose quantity than HFCS; the two beverages using cane sugar recorded an average of $0.25 \mathrm{~g}$ of EFF per $100 \mathrm{ml}$, resulting in $5.6 \%$ more fructose than glucose for the two drinks ${ }^{(14,62)}$.
Although there are other harmful health effects of soft drink consumption that may be reduced by the introduction of HFCS, its introduction in recent times has likely caused an increased risk of FM, particularly in communities where soft drink consumption is high.

It is estimated that, on average, $10 \%$ of an US American's daily energy intake is derived from fructose ${ }^{(8)}$. A study by Vos et al. assessed that fructose consumption per capita in Americans (excluding that which occurs naturally in fruits and vegetables) increased from less than $0.5 \mathrm{~g} / \mathrm{d}$ in 1970 to more than $40 \mathrm{~g} / \mathrm{d}$ in $1997^{(8)}$. This may be due to the increase in consumption of HFCS, with consumption increasing by $26 \%$, from $64 \mathrm{~g} / \mathrm{d}$ in 1970 to 81 $\mathrm{g} / \mathrm{d}$ in 1997 . HFCS contains fructose $(55 \%$ by weight; $56.7 \%$ of total energy content) and glucose ( $42 \%$ by weight; $43.3 \%$ of total energy content) in their monosaccharide forms, thus highlighting a potential increase in fructose consumption from $\mathrm{HFCS}^{(15)}$.

Another study by Vos et al., in 2008, provided important statistics on fructose consumption. Fruit and fruit juices provide the largest amount of fructose for children aged $2-5$ years and adults over the age of 50, whereas for people aged between 12 and 30 years, sugar-sweetened drinks account for nearly half of all fructose consumption, perhaps due to $\operatorname{HFCS}^{(8)}$. The study found that processed food, regardless of food category, is responsible for a significant contribution towards fructose consumption. Seventy-four percentage of fructose consumed originated from foods excluding whole foods and vegetables ${ }^{(8)}$. It is important to highlight that these data are from the USA; surveys for other countries are limited and conclusions drawn from other territories may differ significantly, especially due to the local availability of HFCS.

A study of national HFCS production and diabetes prevalence was conducted by Goran et al in $2013^{(66)}$. It was found that there is a $20 \%$ increase in the prevalence of type 2 diabetes in HFCSproducing countries, with a $P$-value $=0 \cdot 013$. Although the values in the paper are skewed by the significantly higher than average prevalence of type 2 diabetes in the USA (the present study examined type 2 diabetes), it could be argued that due to the estimates of HFCS production, that FM prevalence may follow a similar trend.

\section{Diagnosis of fructose malabsorption}

Diagnosing FM is made difficult due to the fact that symptoms caused by FM can be caused by a number of other conditions, including other sugar intolerances. The current test for FM is the $\mathrm{HBT}^{(67)}$. Excess sugar in the GI tract is fermented by intestinal bacteria, resulting in the production of hydrogen which can be measured during exhalation. The chemical reaction for this is shown in Fig. 3. The patient is given pure fructose to consume and after a period of fasting (usually between 8 and $12 \mathrm{~h}$ ), the patient's breath is collected and analysed for the concentration of gases in the breath sample. Elevated levels of hydrogen may indicate the patient suffers from FM. Typically, a positive test is recorded in the concentration of hydrogen and methane that are greater than $20 \mathrm{ppm}$ above baseline values, recorded prior to the test, after $60 \min ^{(68)}$.

However, there are a number of issues with the HBT. Lee's group estimated that between 8 and $12 \%$ of all patients tested 


\author{
$\mathrm{C}_{6} \mathrm{H}_{12} \mathrm{O}_{6}+\mathrm{H}_{2} \mathrm{O} \rightarrow \mathrm{C}_{2} \mathrm{H}_{4} \mathrm{O}_{2}+\mathrm{C}_{4} \mathrm{H}_{6} \mathrm{O}_{5}+2 \mathrm{H}_{2}$ \\ Fructose + Water $\rightarrow$ Acetic acid + Malic acid + Hydrogen \\ $\mathrm{C}_{4} \mathrm{H}_{6} \mathrm{O}_{5} \rightarrow \mathrm{C}_{3} \mathrm{H}_{6} \mathrm{O}_{3}+\mathrm{CO}_{2}$ \\ Malic acid $\rightarrow$ Lactic acid + Carbon dioxide \\ $2 \mathrm{C}_{6} \mathrm{H}_{12} \mathrm{O}_{6}+2 \mathrm{H}_{2} \rightarrow 2 \mathrm{C}_{6} \mathrm{H}_{14} \mathrm{O}_{6}$ \\ Malic acid + Hydrogen $\rightarrow$ Mannitol
}

Fig. 3. Chemical reaction for the fermentation of fructose by bacteria in the GI $\operatorname{tract}^{(69)}$.

for lactose malabsorption will result in false negatives from the HBT, if tested for hydrogen alone, since many patients will produce methane, rather than hydrogen ${ }^{(70)}$. A key problem with the HBT is the lack of specificity of the test; elevated breath hydrogen can be as a result of a multitude of reasons, including FM, but also potentially SIBO and malabsorption of other carbohydrates, which will need alternative treatments. Furthermore, subjective assessment of diet is needed to fully assess the GI complaints and misdiagnosis is possible. In addition, a number of HBT result in false positives, leading to inaccurate data in the epidemiology of FM. In order to accurately diagnose FM, a fructose-selective analysis of the GI tract is required. Helwig et al. described the HBT as possessing no predictive value for the outcome of fructose-free diets, indicating doubt in the HBT's ability as a predictive test for FM. However, Helwig did also describe a positive correlation between the concentration of hydrogen measured in the HBT and the prevalence of FM symptoms, indicating some validity to the use of $\mathrm{HBT}^{(71)}$. FM cannot be directly diagnosed via the Rome criteria, used for GI complaints. The Rome criteria, used to diagnosed IBS, are in its forth iteration and require a patient to have recurrent abdominal pain at least once a week for 3 months, accompanied by at least two of the following for a positive diagnosis of IBS: a change in stool frequency, a change in stool form or discomfort during defecation ${ }^{(72,73)}$.

\section{Treatment of fructose malabsorption}

The primary method of treating GI complaints, such as IBS, is through dietary change. A common diet change is the low-fermentable oligo-, di-, monosaccharide and polyol (FODMAP) diet. This is a restrictive diet aimed at limiting the group of carbohydrates that are poorly absorbed in the SI and subsequently fermented by intestinal bacteria. Table 1 shows a list of foods that may be prescribed as part of a low FODMAP diet. It should be noted that Tuck et al. showed that the simple addition of glucose to fructose had no effect on HBT results of patients with symptoms of FM, when compared with fructose consumption alone $^{(74)}$.

A low FODMAP diet has been shown to have a beneficial effect in randomised, single-blind, crossover studies. In the present study spearheaded by Halmos et al., patients ( $n 30$ patients with IBS) consumed either a low FOFMAP diet or the average diet of an Australian person ${ }^{(66)}$. Their results showed that $70 \%$ of subjects experienced an improvement in symptoms on the low FODMAP diet. The present study is hindered by a low number of subjects and the subjective nature of the assessment of symptoms improvements.
Although dietary intervention is well-known and relatively straightforward to implement, it is not without complications. The FODMAP diet is somewhat complex and with an absence of FODMAP information on food packaging; support from specialist dietitians is required for sufficient adherence, since clinical studies show that not every patient sees improvements to symptoms on a low FODMAP diet, patient compliance is an issue ${ }^{(75)}$.

In addition, there is little knowledge concerning the longterm health effects of being on a low FODMAP diet. One such issue is the alteration to the ecology of GI bacteria due to the change in diet. Studies by both the Sloan and Chumpitazi groups have found a decrease in bacteria in the SI following adherence to a low FODMAP diet, which has the potential to negatively alter the effect the bacteria have as part of the immune system ${ }^{(76,77)}$. More research is needed to determine the exact changes to the bacterial ecology as a result of a low FODMAP diet, because the microbiology of the intestines plays a key role in health and the immune system.

Another concern is the increased prevalence of eating disorders caused by the need for strict monitoring of food intake. It has been proposed by Halmos and Gibson that patients adhering to strict diet controls are at an increased risk of the eating disorder orthorexia nervosa ${ }^{(78)}$. This disorder is linked to symptoms including an obsessive focus on food choice, planning, purchase, preparation and consumption; food as a source of health rather than pleasure; the belief that particular foods can prevent or cure disease and alter well-being. There is a lack of research into such eating disorders and more study is needed into the management of such conditions, given the prevalence of such disorders could be between 5 and $44 \%$ for patients on strict diets ${ }^{(79)}$. There are also concerns regarding potential nutritional deficiencies associated with being on a low FODMAP diet; more research is needed to ascertain the exact level of deficiency and to what extent such deficiencies cause adverse health effects ${ }^{(80)}$.

An alternative to strict dietary controls is found in gut-directed hypnotherapy. A recent randomised clinical trial showed that gut-directed hypnotherapy led to similar efficacy to treating the symptoms of IBS as a low FODMAP diet, without the increased prevalence of eating disorders ${ }^{(81)}$. However, there is currently limited understanding of the brain-gut axis and the mechanism of how gut-based hypnotherapy improves symptoms and lack of availability of hypnotherapists with suitable training means that such treatment may be inaccessible to most patients $^{(80)}$.

Xylose isomerase has been proposed as a potential treatment of FM in recent years ${ }^{(82)}$. Xylose isomerase is used to convert fructose to glucose in industrial settings and has been shown to produce no allergic response in humans ${ }^{(82)}$. The ability of xylose isomerase to convert between glucose and fructose, shown in Fig. 4, has led to the proposal of its use as a treatment for FM. A double-blind, placebo-controlled study showed a significant decrease in breath hydrogen upon oral administration of xylose isomerase, after ingestion of fructose, as well as significant improvement regarding nausea and abdominal pain, two symptoms related to FM and IBS $^{(82)}$. More research is needed to assess the long-term health effects and to determine which patients are best suited to treatment with xylose isomerase. 
Table 1. Table of high- and low-fermentable oligo-, di-, mono-saccharides and polyol (FODMAP) foods

\begin{tabular}{|c|c|c|}
\hline Types of sugars & High-FODMAP food & Low-FODMAP alternatives \\
\hline Oligosaccharides & $\begin{array}{l}\text { FOS } \\
\text { Grains: wheat-, rye- and barley-based products } \\
\text { Vegetables: onion, garlic, artichokes, leeks, beetroot } \\
\text { and savoy cabbage } \\
\text { Fruits: watermelon, peaches, persimmon, prunes, } \\
\text { nectarines and most dried fruit } \\
\text { GOS } \\
\text { Legumes: red kidney beans, baked beans and soya } \\
\text { beans } \\
\text { Vegetables: beetroot and peas }\end{array}$ & $\begin{array}{l}\text { Fruit: banana, most berries (except boysenberries and blackberries), } \\
\text { grapes, lemon, lime, mandarin, orange, kiwi fruit, pineapple, passion } \\
\text { fruit and rhubarb } \\
\text { Vegetables: capsicum, bok choy, green beans, parsnip, silverbeet, } \\
\text { cucumber, carrots, celery, eggplant, lettuce, potatoes, yams, tomatoes } \\
\text { and zucchini } \\
\text { Grains: wheat-free grains/flour, gluten-free bread or cereal products and } \\
\text { quinoa }\end{array}$ \\
\hline Disaccharides & $\begin{array}{l}\text { Lactose } \\
\text { Dairy products: cows/goat milk and yogurt }\end{array}$ & $\begin{array}{l}\text { Dairy products: lactose-free, almond or rice-based milk, yogurt and ice } \\
\text { cream, hard cheese, feta and cottage cheese }\end{array}$ \\
\hline Monosaccharides & $\begin{array}{l}\text { Fructose (in excess of glucose) } \\
\text { Fruits: apples, pears, watermelon, mango, cherries, } \\
\text { boysenberries and fruit juice from high-fructose } \\
\text { foods } \\
\text { Honey } \\
\text { Sweeteners: high-fructose maize syrup } \\
\text { Vegetable: asparagus and snap peas }\end{array}$ & $\begin{array}{l}\text { Fruit: banana, grapes, honeydew, melon, kiwifruit, lemon, lime, mandarin, } \\
\text { orange, passionfruit, pawpaw and most berries (except boysenberries } \\
\text { and blackberries) } \\
\text { Sweeteners: maple syrup and golden syrup }\end{array}$ \\
\hline Polyols & $\begin{array}{l}\text { Sorbitol } \\
\text { Fruit: apples, pears, avocado, apricots, blackberries, } \\
\text { nectarines, peaches, plums, prunes and watermelon } \\
\text { Mannitol } \\
\text { Vegetables: sweet potato, mushrooms, cauliflower and } \\
\text { snow peas }\end{array}$ & $\begin{array}{l}\text { Sweeteners: maple syrup and sugar (sucrose) } \\
\text { Fruits: banana, grape, honeydew, melon, kiwifruit, lemon, mandarin, } \\
\text { orange, passionfruit and paw paw }\end{array}$ \\
\hline
\end{tabular}

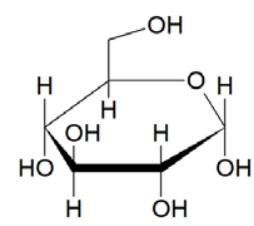

$\alpha$-D-Glucopyranose
Xylose isomerase
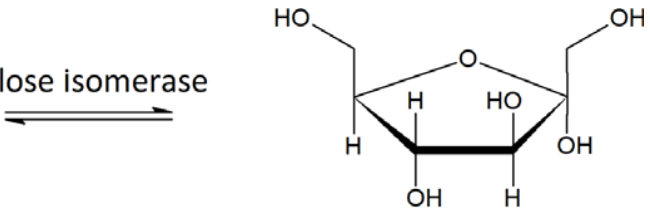

$\alpha$-D-Fructofuranose

Fig. 4. The conversion of glucose to fructose by xylose isomerase ${ }^{(81)}$.

\section{Conclusions and future outlook}

With the increased global consumption of fructose in recent decades comes the increasing prevalence of IBS and other GI complaints caused by FM. However, with limited understanding into the mechanism of fructose absorption and the currently inability to accurately diagnose FM, treatment of such disorders is somewhat difficult.

Current treatment regimens for FM are fraught with limited understanding of the long-term health effects of following such routines. Alternative approaches to treatment, such as the use of medicinal intervention, need to be investigated. It is also important that the relationship between SIBO and FM is investigated thoroughly, so that the symptoms of IBS can be accurately addressed as the result of accurate diagnosis of the causes of IBS. However, this is hindered significantly by the inter-relationship between these two factors and the similarities of the symptoms that SIBO and FM cause. Dietary intervention can prevent the causes of IBS, by removing the nutrients in questions from the GI tract; however, precise determination of the food groups responsible for symptoms can be difficult and as is the case with any diet, patient compliance is often the main factor in the success of these diets.

Our understanding of FM and its role to play in various diseases are still in its infancy. However, it is apparent that FM may have significant role to play in a variety of diseases, not just IBS.

\section{Acknowledgements}

The authors have no other relevant affiliations or financial involvement with any organisation or entity with a financial interest or financial conflict with the subject matter or materials discussed in the manuscript. No writing assistance was utilised in the production of this manuscript.

Conceptualisation: S. P. W., A. L. G. and A. E.; formal analysis: S. P. W. and M. B.; investigation: S. P. W. and M. B.; methodology: S. P. W. and M. B.; project administration: S. P. W., A. L. G. and A. E.; supervision: S. P. W.; writing - original draft: M. B. and S. P. W.; writing - review and editing: S. P.W., A. L. G. and A. E.

We have no conflicts of interest in the publication of this review. 


\section{References}

1. Canavan C, West J \& Card T (2014) The epidemiology of irritable bowel syndrome. Clin Epidemiol 6, 71-80.

2. Holtmann GJ, Ford AC \& Talley NJ (2016) Pathophysiology of irritable bowel syndrome. Lancet Gastroenterol Hepatol 1 , 133-146.

3. Di Nicolantonio JJ \& Lucan SC (2015) Is fructose malabsorption a cause of irritable bowel syndrome? Med Hypotheses $\mathbf{8 5}$, 295-297.

4. Choi YK, Kraft N, Zimmerman B, et al. (2008) Fructose Intolerance in IBS and Utility of Fructose-Restricted Diet. J Clin Gastroenterol 42, 233-238.

5. Gaby AR (2005) Dietary fructose review adverse effects of dietary fructose. vol. 10, alternative medicine review. https:// pubmed.ncbi.nlm.nih.gov/16366738/ (accessed 8 October 2020).

6. Ledochowski M, Sperner-Unterweger B, Widner B, et al. (1998) Fructose malabsorption is associated with early signs of mental depression. Eur J Med Res 3, 295-298.

7. Noelting J \& Di Baise JK (2015) Mechanisms of fructose absorption. Clin Transl Gastroenterol 6, e120.

8. Vos MB, Kimmons JE, Gillespie C, et al. (2008) Dietary fructose consumption among US children and adults: the Third National Health and Nutrition Examination Survey. Medscape J Med 10, 160.

9. Bray GA, Nielsen SJ \& Popkin BM (2004) Consumption of high-fructose corn syrup in beverages may play a role in the epidemic of obesity. Am J Clin Nutr 79, 537-543.

10. Ma M, Long Q, Chen F, et al. (2019) Nutrition management of congenital glucose-galactose malabsorption: case report of a Chinese infant. Medicine 98.

11. Burke M (2019) Carbohydrate intolerance and disaccharidase measurement - a mini-review. Clin biochemist Rev 40, 167-174.

12. Moskowitz HR (1970) Ratio scales of sugar sweetness. Percept Psychophys 7, 315-320.

13. Duffey KJ \& Popkin BM (2008) High-fructose corn syrup: is this what's for dinner? Am J Clin Nutr 88, 1722S-1732S.

14. Ventura EE, Davis JN \& Goran MI (2011) Sugar content of popular sweetened beverages based on objective laboratory analysis: focus on fructose content. Obesity 19, 868-874.

15. Bray GA, Nielsen SJ \& Popkin BM (2004) Consumption of high-fructose corn syrup in beverages may play a role in the epidemic of obesity. Am J Clin Nutr 79, 537-543.

16. Popkin BM \& Nielsen SJ (2003) The sweetening of the world's diet. Obes Res 11, 1325-1332.

17. Kawasaki $T$, Akanuma $H$ \& Yamanouchi $T$ (2002) Increased fructose concentrations in blood and urine in patients with diabetes. Diabetes Care 25, 353.

18. Leturque A, Brot-Laroche E, le Gall M, et al. (2005) The role of GLUT2 in dietary sugar handling. J Physiol Biochem 61, 529.

19. Douard V \& Ferraris RP (2008) Regulation of the fructose transporter GLUT5 in health and disease. Am J Physiol-Endocrinol Metab 295, E227-E237.

20. White PS, Jensen SJ, Rajalingam V, et al. (1998) Physical mapping of the CA6, ENO1, SLC2A5 (GLUT5) genes, reassignment of SLC2A5 to 1p36.2. Cytogenetic Genom Res 81, 60-64.

21. Li Q, Manolescu A, Ritzel M, et al. (2004) Cloning and functional characterization of the human GLUT7 isoform SLC2A7 from the small intestine. Am J Physiol-Gastrointestinal Liver Physiol 287, G236-G242.

22. Doege H, Bocianski A, Scheepers A, et al. (2001) Characterization of human glucose transporter (GLUT) 11 (encoded by SLC2A11), a novel sugar-transport facilitator specifically expressed in heart and skeletal muscle. Biochem J359, 443-449.
23. Manolescu A, Salas-Burgos AM, Fischbarg J, et al. (2005) Identification of a hydrophobic residue as a key determinant of fructose transport by the facilitative hexose transporter SLC2A7 (GLUT7). J Biol Chem 280, 42978-42983.

24. Dominguez Rieg JA \& Rieg T (2019) What does sodium-glucose co-transporter 1 inhibition add: prospects for dual inhibition. Diabetes Obes Metab 2, 43-52.

25. Blakemore SJ, Aledo JC, James J, et al. (1995) The GLUT5 hexose transporter is also localized to the basolateral membrane of the human jejunum. Biochem J 309, 7-12.

26. Shu H-J, Isenberg K, Cormier RJ, et al. (2006) Expression of fructose sensitive glucose transporter in the brains of fructose-fed rats. Neuroscience 140, 889-895.

27. Payne J, Maher F, Simpson I, et al. (1997) Glucose transporter glut 5 expression in microglial cells. Glia 21, 327-331.

28. Nualart F, Godoy A \& Reinicke K (1999) Expression of the hexose transporters GLUT1 and GLUT2 during the early development of the human brain. Brain Res 824, 97-104.

29. Dyer J, Wood IS, Palejwala A, et al. (2002) Expression of monosaccharide transporters in intestine of diabetic humans. Am J Physiol-Gastrointestinal Liver Physiol 282, G241-G248.

30. Pitkänen E (1996) Mannose, mannitol, fructose and 1,5-anhydroglucitol concentrations measured by gas chromatography/mass spectrometry in blood plasma of diabetic patients. Clinica Chimica Acta 251, 91-103.

31. Buddington RK \& Diamond JM (1989) Ontogenetic development of intestinal nutrient transporters. Ann Rev Physiol 51, 601-617.

32. Ferraris RP (2001) Dietary and developmental regulation of intestinal sugar transport. Biochem J 360, 265-276.

33. Duro D, Rising R, Cedillo M, et al. (2002) Association between infantile colic and carbohydrate malabsorption from fruit juices in infancy. Pediatrics 109, 797.

34. Nobigrot T, Chasalow FI \& Lifshitz F (1997) Carbohydrate absorption from one serving of fruit juice in young children: age and carbohydrate composition effects. J Am Coll Nutr 16, 152-158.

35. Chan KK, Chan JYW, Chung KKW, et al. (2004) Inhibition of cell proliferation in human breast tumor cells by antisense oligonucleotides against facilitative glucose transporter 5 . J Cell Biochem 93, 1134-1142.

36. Godoy A, Ulloa V, Rodríguez F, et al. (2006) Differential subcellular distribution of glucose transporters GLUT1-6 and GLUT9 in human cancer: ultrastructural localization of GLUT1 and GLUT5 in breast tumor tissues. J Cell Physiol 207, 614-627.

37. Levi J, Cheng Z, Gheysens O, et al. (2007) Fluorescent fructose derivatives for imaging breast cancer cells. Bioconjugate Chem 18, 628-634

38. Peralta S, Cottone C, Doveri T, et al. (2009) Small intestine bacterial overgrowth and irritable bowel syndrome-related symptoms: experience with Rifaximin. World J Gastroenterol 15, 2628-2631.

39. Lin HC (2004) Small intestinal bacterial overgrowth: a framework for understanding irritable bowel syndrome. JAMA 292, $852-858$.

40. Ghoshal UC, Ghoshal U, Das K, et al. (2006) Utility of hydrogen breath tests in diagnosis of small intestinal bacterial overgrowth in malabsorption syndrome and its relationship with oro-cecal transit time. https://pubmed.ncbi.nlm.nih.gov/16567886/ (accessed 8 October 2020).

41. Rumessen JJ (1992) Fructose and related food carbohydrates: sources, intake, absorption, and clinical implications. Scand J Gastroenterol 27, 819-828.

42. Fedewa A \& Rao SSC (2014) Dietary fructose intolerance, fructan intolerance and FODMAPs. Curr Gastroenterol Rep 16, 370 . 
43. Shepherd SJ, Parker FC, Muir JG, et al. (2008) Dietary triggers of abdominal symptoms in patients with irritable bowel syndrome: randomized placebo-controlled evidence. Clin Gastroenterol Hepatol 6, 765-771.

44. Attaluri A, Paulson J, Jackson M, et al. (2009) Dietary fructan intolerance: a new unrecognized problem in IBS: 57. Neurogastroenterol Motil 21.

45. Oku T, Tokunaga T \& Hosoya N (1984) Nondigestibility of a New Sweetener, "Neosugar," in the Rat. J Nutr 114, 1574-1581.

46. Stone-Dorshow T \& Levitt MD (1987) Gaseous response to ingestion of a poorly absorbed fructo-oligosaccharide sweetener. Am J Clin Nutr 46, 61-65.

47. Kleessen B, Hartmann L \& Blaut M (2003) Fructans in the diet cause alterations of intestinal mucosal architecture, released mucins and mucosa-associated bifidobacteria in gnotobiotic rats. Br J Nutr 89, 597-606.

48. Rumessen JJ \& Gudmand-Høyer E (1998) Fructans of chicory: intestinal transport and fermentation of different chain lengths and relation to fructose and sorbitol malabsorption. Am J Clin Nutr 68, 357-364.

49. Cummings JH \& Macfarlane GT (2002) Gastrointestinal effects of prebiotics. BrJ Nutr 87, S145-S151.

50. Hidaka H, Eida T, Takizawa T, et al. (1986) Effects of fructooligosaccharides on intestinal flora and human health. Bifidobacteria Microflora 5, 37-50.

51. Jung KW, Seo M, Cho YH, et al. (2018) Prevalence of fructose malabsorption in patients with irritable bowel syndrome after excluding small intestinal bacterial overgrowth. I Neurogastroenterol Motil 24, 307-316.

52. Wang X \& Gibson GR (1993) Effects of the in vitro fermentation of oligofructose and inulin by bacteria growing in the human large intestine. J Appl Bacteriol 75, 373-380.

53. Rivière A, Selak M, Lantin D, et al. (2016) Bifidobacteria and Butyrate-Producing Colon Bacteria: importance and Strategies for Their Stimulation in the Human Gut. Front Microbiol 7, 979.

54. Markowiak P \& Śliżewska K (2017) Effects of probiotics, prebiotics, and synbiotics on human health. Nutrients 9, 1021.

55. Cherbut $C$ (2002) Inulin and oligofructose in the dietary fibre concept. Br J Nutr 87, S159-S162.

56. Barrett J \& Glbson PR (2007) Clinical ramifications of malabsorption of fructose and other short-chain carbohydrates. Pract Gastroenterol 31, 51-65.

57. Poeker SA, Geirnaert A, Berchtold L, et al. (2018) Understanding the prebiotic potential of different dietary fibers using an in vitro continuous adult fermentation model (PolyFermS). Sci Rep 8, 4318.

58. Parnell JA \& Reimer RA (2012) Prebiotic fiber modulation of the gut microbiota improves risk factors for obesity and the metabolic syndrome. Gut Microbes 3, 29-34.

59. Trelis M, Taroncher-Ferrer S, Gozalbo M, et al. (2019) Giardia intestinalis and fructose malabsorption: a frequent association. Nutrients 11, 2973.

60. Walker RW, Dumke KA \& Goran MI (2014) Fructose content in popular beverages made with and without high-fructose corn syrup. Nutrition 30, 928-935.

61. Jones HF, Burt E, Dowling K, et al. (2011) Effect of age on fructose malabsorption in children presenting with gastrointestinal symptoms. J Pediatr Gastroenterol Nutr 52, 581-584.

62. Szilagyi A, Malolepszy P, Yesovitch S, et al. (2007) Fructose malabsorption may be gender dependent and fails to show compensation by colonic adaptation. Dig Dis Sci $\mathbf{5 2}$, 2999-3004.

63. Macha S, VanWagoner A \& Tolia V (2004) P0845 fructose malabsorption in pediatrics. J Pediatr Gastroenterol Nutr 39, $\mathrm{S} 378$.
64. Halmos EP, Power VA, Shepherd SJ, et al. (2014) A diet low in FODMAPs reduces symptoms of irritable bowel syndrome. Gastroenterology 146, 67-75.

65. Nanayakkara WS, Skidmore PM, O'Brien L, et al. (2016) Efficacy of the low FODMAP diet for treating irritable bowel syndrome: the evidence to date. Clin Exp Gastroenterol 9, 131-142.

66. Martínez-Azcona O, Moreno-Álvarez A, Seoane-Pillado T, et al. (2019) Fructose malabsorption in asymptomatic children and in patients with functional chronic abdominal pain: a prospective comparative study. Eur J Pediatr 178, 1395-1403.

67. Peterson WH \& Fred EB (1920) Fermentation of fructose by Lactobacillus pentoaceticus, n. sp. J Biol Chem 41, 431-450.

68. Lee MJ, Barrie S \& Levinson U (1996) Breath testing in intestinal disaccharidase deficiency and bacterial overgrowth of the small intestine. J Nutr Environ Med 6, 43-54.

69. Helwig U, Koch AK, Koppka N, et al. (2019) The predictive value of the hydrogen breath test in the diagnosis of fructose malabsorption. Digestion 99, 140-147.

70. Chang L (2017) Updates to the Rome criteria for irritable bowel syndrome. Gastroenterol Hepatol 13, 304-306.

71. Schmulson MJ \& Drossman DA (2017) What is new in Rome IV. J Neurogastroenterol Motil 23, 151-163.

72. Tuck CJ, Ross LA, Gibson PR, et al. (2017) Adding glucose to food and solutions to enhance fructose absorption is not effective in preventing fructose-induced functional gastrointestinal symptoms: randomised controlled trials in patients with fructose malabsorption. J Hum Nutr Diet 30, 73-82.

73. Komericki $\mathrm{P}$, Akkilic-Materna M, Komericki-Strimitzer T, et al. (2012) Oral xylose isomerase decreases breath hydrogen excretion and improves gastrointestinal symptoms in fructose malabsorption - a double-blind, placebo-controlled study. Aliment Pharmacol Ther 36, 980-987.

74. Manichanh C, Eck A, Varela E, et al. (2014) Anal gas evacuation and colonic microbiota in patients with flatulence: effect of diet. Gut 63, 401-408.

75. Chumpitazi BP, Cope JL, Hollister EB, et al. (2015) Randomised clinical trial: gut microbiome biomarkers are associated with clinical response to a low FODMAP diet in children with the irritable bowel syndrome. Aliment Pharmacol Therapeut 42, 418-427.

76. Halmos EP \& Gibson PR (2019) Controversies and reality of the FODMAP diet for patients with irritable bowel syndrome. J Gastroenterol Hepatol 34, 1134-1142.

77. Satherley R, Howard R \& Higgs S (2015) Disordered eating practices in gastrointestinal disorders. Appetite 84, 240-250.

78. Blow DM, Collyer CA, Goldberg JD, et al. (1992) Structure and mechanism of D-xylose isomerase. Faraday Discuss $\mathbf{9 3}$, $67-73$.

79. Lindfors $\mathrm{P}$, Unge $\mathrm{P}$, Arvidsson $\mathrm{P}$, et al. (2012) Effects of gut-directed hypnotherapy on IBS in different clinical settings-results from two randomized, controlled trials. Offic J Am Coll Gastroenterol 107, 276-285.

80. Komericki P, Akkilic-Materna M, Strimitzer T, et al. (2012) Oral xylose isomerase decreases breath hydrogen excretion and improves gastrointestinal symptoms in fructose malabsorption: a double-blind, placebo-controlled study. Aliment Pharmacol Ther 36, 980-987.

81. EFSA Panel on Food Contact Materials E and PA (CEP), Silano V, Barat Baviera JM, et al. (2020) Safety evaluation of the food enzyme xylose isomerase from the genetically modified Streptomyces rubiginosus strain DP-Pzn37. EFSA J 18, e05978.

82. Singh RS, Singh T \& Pandey A (2019) Microbial Enzymes: an Overview. Advances in Enzyme Technology. Amsterdam: Elsevier. 